Proceedings of SALT 31: 166-183, 2021

\title{
A post-suppositional account of associative plurals in Burmese*
}

\author{
Keely New \\ Massachusetts Institute of Technology
}

\begin{abstract}
I investigate the interpretation of the associative plural tóldó in Colloquial Burmese based on original fieldwork. I report that in a conjunction of associative plurals, there is an available reading where the named individuals in the conjunction internally satisfy the plural requirement. I call this the internal plural reading, a reading which has not been previously observed in the literature. I propose that the named individuals in a conjunction of associative plurals can satisfy each other's plural requirement if the Burmese associative plural has a meaning that is postsuppositional. The proposal is inspired by Brasoveanu \& Szabolcsi 2013's treatment of conjunctions of additive phrases in some languages, but our proposals crucially differ in that associative plurals contribute assertive meaning rather than not-at-issue meaning.
\end{abstract}

Keywords: Burmese, plurality, associative plurals, post-suppositions

\section{Introduction}

Plural morphemes are descriptively identified by its requirement that the nominal it forms has a referent that contains at least two atoms. This is often called the multiplicity inference of plurals (see e.g. Zweig 2009). Colloquial Burmese has two types of nominal morphology that seem to give us multiplicity inferences: the general plural tweldwe and the associative plural tóldó. The example in (1) demonstrates the multiplicity inference of the general plural tweldwe and the example in (2) demonstrates it for the associative plural tóldó.

* I am grateful to Michael Yoshitaka Erlewine for extensive discussion of the data and analysis in this work. I also thank Phyo Thi Han, Phyo Thura Htay, and Nyan Lin Htoo for discussion of the Burmese data and Meghan Lim for assistance with transcsription. For comments and feedback that has led to the development of important many ideas here, I thank Kenyon Branan, Chris Davis, Patrick Elliott, Hadas Kotek, Shen Zheng, Ryan Walter Smith, Michelle Yuan, and the audience at SALT 31 and TripleA 8. This work was done at the National University of Singapore, supported by grant R-103-000-178-133 to Michael Yoshitaka Erlewine. All errors are my own. 
A post-suppositional account of associative plurals in Burmese

\section{(1) General plural twe/dwe:}

$$
\begin{aligned}
& \text { Sú=gá } \quad\left[\text { DP s'ăya-dwe } \quad(=g o) \text { twé-géh-deh. }{ }^{1}\right. \\
& \text { Suu=NOM teacher-PL }=\text { ACC meet-PAST-NFUT }
\end{aligned}
$$

'Suu met teachers.'

$\rightsquigarrow$ Suu met at least two teachers.

\section{(2) Associative plural tóldó:}

$$
\begin{aligned}
& \text { Sú=gá } \quad \text { [DP Hla Hla-dó }] \quad(=\text { go }) \text { twé-géh-deh. } \\
& \text { Suu=NOM } \quad \text { Hla Hla-ASSOC }=\text { ACC meet-PAST-NFUT }
\end{aligned}
$$

'Suu met Hla Hla and her associate(s).'

$\rightsquigarrow$ Suu met Hlalhla.

$\rightsquigarrow$ Suu met at least one of Hla Hla's social associates.

Even though both types of plural phrases have at least two individuals in each of their referents, the source of the multiplicity inference could be different. In particular, notice that the two entailments reported under (2) taken together already guarantee that the referent of Hla Hla-dó will contain at least two individuals.

This paper is concerned with developing a precise semantics for the associative plural tóldó. An important data point for the semantics of tóldó comes from the interpretation of the conjunction of associative tóldó plurals in (3). (3) is true just in case Suu met two people, namely Hla Hla and Aung, as long as they are each other's associates.

$$
\begin{array}{llll}
\text { Sú=gá Hla Hla-dó } \quad(=n e ́ h) & \text { Aun-dó=go twé-géh-deh. } \\
\text { Suu=NOM Hla Hla-ASSOC } & =\text { CONJ Aung-ASSOC=ACC meet-PAST-NFUT }
\end{array}
$$

'Suu met Hla Hla (and her associate(s)) and Aung (and his associate(s)).'

This result is surprising because given that there is associative plural morphology tóldó on each conjunct which regularly introduces a multiplicity inference, we therefore might expect that the conjunction in (3) requires at least four people in its referent. In fact, this is the interpretation of the conjunction of twe/dwe plurals in (4), which would be natural only if Suu met at least four people in total.

(4) Sú=gá s’ăya-dwe (=néh) caùndhà-dwe=go twé-géh-deh.

Suu=NOM teacher-PL $=$ CONJ student-PL=ACC meet-PAST-NFUT

'Suu met teachers and students.'

1 I follow the romanisation for Burmese employed in Okell (1994, 2010). The coda $q$ represents a glottal stop and $\breve{a}$ indicates a schwa. Underlyingly unvoiced syllable-intial consonants are voiced word-internally except after a glottal stop or a schwa. 
I propose that the contrast between (3) and (4) can be understood if we say that Hla Hla and Aung in (3) can satisfy each other's associative tóldó requirement. In order to do that, tóldó's associative requirement would have to be delayed such that it can be evaluated after the other meanings of the utterance have been added to the context. Formally, I will model tóldó's requirement as a post-supposition following Farkas (2002), Lauer (2009), Brasoveanu (2013) and subsequent work.

The rest of the paper is organised as follows: section 2 introduces Burmese bare nominals and plural morphemes. Section 3 presents data on plural conjunction which will motivate the proposal in section 4 . Section 5 concludes with an eye toward cross-linguistic extensions.

\section{Burmese and its plural morphemes}

To begin, I first give a brief introduction to features of Burmese nominal structure that will be relevant for the discussion in this paper. I will also introduce the general plural morpheme tweldwe and the associative plural tóldó.

Burmese is a head-final language with default SOV word order and nominativeaccusative case alignment. Case-drop is optional and not correlated with definiteness or animacy (Lim \& Erlewine to appear; Erlewine \& Lim 2020). Lim \& Erlewine (2020) provide the following schema in (5) for the basic structure of noun phrases in Burmese based on descriptions in Soe (1999: ch. 3) and Simpson (2005). Plural markers - both the general plural and the associative plural that I will discuss lateroccur post-nominally before the numeral and classifier.

\section{Burmese noun phrase schema:}

(Dem) (RC) N (Adj) (PL) (Num-CL)

Bare nouns in Burmese are not number-neutral and necessarily pick out singular referents salient in the context:

(6) Context: You and Maung Maung are at Hla Hla's house. She has one dog, who is playing with Maung Maung. You tell Hla Hla:

K'wè=gá Maun Maun=go caiq-ne-deh. $\operatorname{dog}=$ NOM Maung Maung=ACC like-PROG-NFUT

'The dog likes Maung Maung.' ～(Lim \& Erlewine to appear: 7)

In order to pick out a plural referent, speakers must use the general plural marker tweldwe, as shown in (7). 
A post-suppositional account of associative plurals in Burmese

(7) Context: You and Maung Maung are at Hla Hla's house. She has four dogs and all of them are playing with Maung Maung. You tell Hla Hla:

K'wè-*(dwe)=gá Maun Maun=go caiq-ne-deh.

$\operatorname{dog}_{-} *(\mathrm{PL})=$ NOM Maung Maung=ACC like-PROG-NFUT

'The dogs like Maung Maung.'

As mentioned before, there are at least two types of plurals attested in Burmese. The first is the general plural morpheme tweldwe. ${ }^{2}$ As can be gleaned from the translation, the plural noun phrase in (8) gives rise to a multiplicity inference similar to English bare plural indefinites: s' $\breve{y} y a-d w e$, 'teacher-PL' denotes a group of at least two individuals that each have the property of being a teacher.

General plural twe/dwe:

Sú=gá s’ăya-dwe=go twé-géh-deh.

$\mathrm{Suu}=\mathrm{NOM}$ teacher-PL $=$ ACC meet-PAST-NFUT

'Suu met teachers.'

$\rightsquigarrow$ Suu met at least two teachers.

The second type of plural in Burmese is the associative plural tóldó. In their reference grammar, Jenny \& Hnin Tun (2016) write that “...tóldó indicates that the referent is accompanied by people belonging to him/her, without being of the same kind." (Jenny \& Hnin Tun 2016: 130). As an example, consider (9) below which contrasts minimally with (8) in the choice of plural morpheme of the object noun phrase.

\section{Associative plural tóldó:}

Sú=gá s'ăya-dó=go twé-géh-deh.

Suu=NOM teacher-ASSOC $=$ ACC meet-PAST-NFUT

'Suu met teachers.' or

'Suu met at least one teacher and their associate(s).'

Like the general plural tweldwe, associative tóldó has a multiplicity inference, requiring at least two individuals in its referent. Unlike the general plural, the referent of tóldó can be what has been called "non-uniform" (Moravcsik 2003; Nakanishi \& Tomioka 2004) or "non-homogeneous"3 (den Besten 1996; Smith 2020) that is, not every part of the plurality of an associative noun phrase needs to match the description of the nominal host. For example, not every individual of the referent of $s$ 'ăya-dó, 'teacher-ASSOC' in (9) needs to be a teacher. What is required

2 There is another general plural myà which is more common in formal and literary Burmese. I do not discuss myà in this paper but see Soe (1999: 57ff), Jenny \& Hnin Tun (2016) etc. 
is that the referent includes at least one teacher but potentially also associates of the teacher(s). An associate can be anyone they are in a contextually salient social relationship with, for example a family member, friend, or co-worker.

Crosslinguistically, a property characteristic of associative plurals is its ability to combine with proper names (Moravcsik 2003), further illustrating the non-uniformity of the plurality. As noted by Soe (1999: 57), Burmese associative plural tóldó also does this, and I show this in (10). Although there is a possible reading of (10) that means that Suu met multiple people named Hla Hla, the more salient reading is that Su met Hla Hla and her associates. The general plural tweldwe, on the other hand, cannot combine with proper names.

Tó/dó can combine with a proper name:

Sú=gá Hla Hla-dó/*dwe=go twé-géh-deh.

Suu=NOM Hla Hla-ASSOC/*PL=ACC meet-PAST-NFUT

'Suu met Hla Hla and her associate(s).'

\subsection{Semantics of $t w e / d w e$}

Although not the focus of the present paper, I propose here that the semantics of the Burmese general plural tweldwe mirrors what has been proposed for bare plurals in English and other languages. Specifically, I argue for the weak theory of plurals over the strong theory (see e.g. Sauerland, Anderssen \& Yatsushiro 2005 and Zweig 2009 for an overview). Under the strong theory of plurals, the bare plural is defined only if its presupposition that the referent is non-atomic is satisfied. The weak theory of plurals argues that the bare plural is actually number-netural and the multiplicity inference observed in most contexts is a result of a pragmatic inference due to competition with the singular. The weak theory is developed in Krifka 2004, Sauerland et al. 2005, Spector 2007 and Zweig 2009 among others. Crucial support for this view comes from the observation that the multiplicity inference of the general plural is absent in downward-entailing contexts. For example, we might expect that the negation of (11a) would logically also negate the multiplicity inference of the bare plural. It turns out that (11b) is not equivalent to the logical negation of (11a): it does not mean that the homework doesn't contain multiple difficult problems.

3 The use of (non-)homogeneity here is different from another notion of homogeneity in the plural literature which is concerned with explaining why sentences with definite plurals do not have complementary truth conditions with their negations (see e.g. Schwarzschild 1996, Löbner 2000, Gajewski 2005 among others). In the literature on associative plurals, den Besten 1996 and Smith 2020 use the term to describe whether all of the members of a plural group satisfy the same nominal description. To avoid this confusion, I use uniformity in the rest of the paper. 
A post-suppositional account of associative plurals in Burmese

(11) a. The homework contains difficult problems.

$\rightsquigarrow$ The homework contains more than one difficult problem.

b. The homework doesn't contain difficult problems

$\rightsquigarrow$ The homework contains zero difficult problems.

$\not \rightarrow$ The homework doesn't contain more than one difficult problem.

(Spector 2007: 243)

The same observation can be shown when a bare plural is embedded in the antecedent of a conditional. The conditional in (12) suggests that the UN envoy does not expect to meet any senior officials at all, not that he expects to meet at most one.

(12) If the UN envoy meets senior government officials on his latest visit to the region, he will be surprised.

$\rightsquigarrow$ If the UN envoy meets one or more senior government officials, he will be surprised.

$\not \rightarrow$ If the UN envoy meets more than one senior government officials, he will be surprised.

(Zweig 2009: 361)

Just like English bare plurals, the multiplicity inference of Burmese twe/dwe disappears under negation (13) and in conditionals (14). (13) does not mean that the speaker didn't meet multiple police officers, which is what we might expect with a plural description in the scope of logical negation. Likewise, the conditional statement in (14) means that Suu will be happy as long as she meets one teacher; it is not required that Suu meets more than one teacher.

(13) No multiplicity inference under negation:

$\mathrm{Nga}=$ gá yèh-dwe mă-twé-géh-bù.

$1=$ NOM police-PL NEG-meet-PAST-NEG

'I didn't meet police officers.'

True if the speaker met zero police officers.

$\underline{\text { False }}$ if the speaker met one or more police officers.

\section{(14) No multiplicity inference in conditionals:}

[Sú=gá s’ăya-dwe=go twé-yin], Sú=gá pyaw-meh.

Suu=NOM teacher-PL=ACC meet-if $\quad$ Suu=NOM happy-FUT

$\rightsquigarrow$ If Suu meets one or more teacher, Suu will be happy.

Thus, I claim that just like the English bare plural, the general plural marker tweldwe in Burmese is a weak plural. In many cases, tweldwe has a multiplicity inference because it is subject to pragmatic comparison with the singular and therefore cannot be used when the singular is possible. 


\section{The internal plural reading}

In section 2, I showed that descriptively, tweldwe and tóldó both introduce multiplicity inferences. In this section, I present data from the conjunction of plurals to motivate that in spite of this similarity, the semantics of the associative plural tóldó must be very different from the semantics of the general plural tweldwe proposed in section 2.1.

First, consider the conjunction of tweldwe plural phrases in (15). The overt conjunction néh is optional and often dropped. (15) is natural and true if Suu met at least two teachers and at least two students. The conjunction is judged as unnatural if Suu only met two individuals, even if they happen to be both teachers and students a the same time. In other words, (15) is most natural when there are at least four individuals in the referent. Given that there is plural morphology on each conjunct and that each plural morpheme gives rise to its own multiplicity inference in the cases we have seen, the interpretation of the conjunction of plurals formed with tweldwe is unsurprising.

Sú=gá s’ăya-dwe (=néh) caùndhà-dwe=go twé-géh-deh.

Suu $=$ NOM teacher-PL $=$ CONJ student-PL $=$ ACC meet-PAST-NFUT

'Suu met teachers and students.'

What is surprising is that the conjunction formed with tóldó plurals does not require more than the named individuals in its referent, in spite of the multiplicity inference otherwise observed with tóldó plural phrases. For example, the utterance in (16) can naturally be uttered in a context where Suu met only Hla Hla and Aung as long as Hla Hla and Aung are associates of each other. (16) does not require that Suu met any unnamed associates.

Conjunction of tóldó DPs:

$$
\begin{aligned}
& \text { Sú=gá Hla Hla-dó } \quad(=\text { néh }) \text { Aun-dó=go } \quad \text { twé-géh-deh. } \\
& \text { Suu=NOM Hla Hla-ASSOC }=\text { CONJ Aung-ASSOC=ACC meet-PAST-NFUT }
\end{aligned}
$$

'Suu met Hla Hla (and her associate(s)) and Aung (and his associate(s)).'

$\rightsquigarrow$ Suu met at least two people (Hla Hla and Aung)

$\Varangle \rightarrow$ Suu met any unnamed associates.

To summarise, we have just seen that in a X-tweldwe Y-tweldwe conjunction, each of the plural morphemes introduce their own multiplicity inference, and thus the conjunction is natural with at least four individuals in its referent. As I alluded to above, there is some expectation that the two groups denoted by the conjunction are distinct and do not overlap. Notice that it is also true that the English conjunction 
A post-suppositional account of associative plurals in Burmese

"teachers and students" is unnatural, at best, if there are only two individuals who happen to be both teachers and students. To my knowledge, this observation has not been noticed or explained in existing literature. I do not intend to address this question here; it is more important for present purposes that this requirement does not hold for the associative plural conjunction X-tóldó Y-tóldó which is a natural way to describe two individuals namely $\mathrm{X}$ and $\mathrm{Y}$, as long as they are each other's associates. I call this the internal plural reading, the intuition being that the multiplicity inference of tóldó can be satisfied internally within the plural conjunction.

\section{Proposal}

I propose that the internal plural reading can be explained if a component of the meaning of tóldó is post-suppositional. Before explaining my proposal in detail, I will first give a brief overview of post-suppositions.

\subsection{Introduction to post-suppositions}

Post-suppositional meanings are propositions checked after other components of meaning of the sentence have been integrated into the context (Lauer 2009; Brasoveanu 2013). Post-suppositions were named as such as they contrast with presuppositions which must be true before updating with the sentence's at-issue content. Some of the phenomena analysed as 'post-suppositional' are indeed like presuppositions in that a failure to satisfy post-suppositional conditions will result in infelicity (e.g. Bumford 2017, Brasoveanu \& Szabolcsi 2013). Nonetheless, there have been proposals of post-suppositions that lead to falsity or ungrammaticality rather than presuppositional failure if the post-suppositional conditions are not met (e.g. Brasoveanu 2013, Kuhn 2021). I adopt the view of Charlow 2016 and Kuhn 2021 that what is post-suppositional or not should be a matter of evaluation order, rather than the 'kind' of meaning.

To see how post-suppositions work, I will illustrate using Brasoveanu \& Szabolcsi 2013's analysis of additive particles. Brasoveanu \& Szabolcsi 2013 adopt post-suppositions to explain what they refer to as symmetrical A-TOO B-TOO constructions found in languages such as Japanese, Hungarian, Russian, and Hebrew. To see the puzzle, first observe that the use of the Japanese additive particle mo, such as in (17), normally gives rise to a requirement that the predicate is true of someone other than its host: (17) requires that someone other than Taro ran away. 


\section{(17) Japanese additive mo:}

Taro-mo hashitta.

Taro-also ran

'Taro, too, ran away.' (based on Brasoveanu \& Szabolcsi 2013: 55)

Now, observe that the bare conjunction of mo phrases in (18) does not require that anyone other than Taro and Hanako ran away. Such constructions are what they refer to as "symmetrical A-TOO B-TOO" constructions.

\section{(18) Symmetrical A-TOO B-TOO in Japanese:}

Taro-mo Hanako-mo hashitta.

Taro-also Hanako-also ran

'Taro as well as Hanako ran away.'

(ibid.)

The basic insight of Brasoveanu \& Szabolcsi (2013) is that Taro and Hanako in (18) satisfy the requirements imposed by each other's mo's. They propose that this can be done by classifying the requirement of additive particle mo as a postsupposition rather than a pre-supposition, as is standardly assumed. To see how this works, I will give a sketch of the proposal using paraphrases in the style of Kuhn (2021), where post-suppositions are indicated by underline. (19) is the paraphrase for the meaning of (17) above. The at-issue content that Taro ran away is first added to the context. After that, the additive requirement that someone other than Taro ran away is then evaluated as a non-assertive felicity condition. Since the additive requirement is not satisfied by the primary meaning itself, it behaves as a (not-atissue) requirement on the input context, leading to an apparent presupposition.

Analysis by paraphrase for (17):

Taro ran away. Someone other than Taro ran away.

The meaning of the A-TOO B-TOO construction in (18) is paraphrased in (20). As before, the additive requirements on both conjuncts are evaluated after the sentence is uttered. Crucially, after updating with the primary meaning of the sentence, the context necessarily satisfies the post-suppositions, regardless of the input context. This lets Hanako satisfy the additive requirement of Taro-mo and Taro satisfy the additive requirement of Hanako-mo. This explains why the sentence does not require that anyone other than Taro or Hanako ran away in the input context.

\section{(20) Analysis by paraphrase for (18):}

Taro ran away. Hanako ran away. Someone other than Taro ran away. Someone other than Hanako ran away. 
A post-suppositional account of associative plurals in Burmese

\subsection{Burmese associative plurals as post-suppositions}

I propose that the associative requirement of Burmese tóldó is also post-suppositional. Formally, my proposal will make reference to two notions of association sets. First, I define the notion ASSOC as a function mapping an individual to the set of individuals standing in a contextually salient relationship to it. Therefore, the ASSOC set of Hla $H l a$, for example, will contain individuals who are in a contextually salient social relationship with Hla Hla: for instance, Aung and Maung Maung. The ASsOC of Hla Hla does not include Hla Hla herself, as an individual is not considered to be in a social relationship with themself.

$$
\begin{aligned}
& \operatorname{ASSOC}(\mathrm{x})=\{\mathrm{y} \mid<\mathrm{x}, \mathrm{y}>\text { is in a contextually salient social relationship }\} \\
& \operatorname{ASSOC}(\text { Hla Hla })=\{\text { Aung, Maung Maung ... }
\end{aligned}
$$

For the second notion of association sets, I adopt Smith 2020's notion of ASET. Smith defines ASET as in (24) as an "inclusive mixture" of $\mathrm{x}$ and its associates. In Smith's terms, an inclusive mixture of two sets is the sum of the elements of the algebraic closure (*) of both sets with elements from the same set, as given in (23). As Smith notes, defining I-MIX in such a way ensures that both ${ }^{*} \mathrm{P}$ and ${ }^{*} \mathrm{Q}$ are subsets of the resulting set.

$$
\llbracket \mathrm{I}-\mathrm{MIX}(\mathrm{P}, \mathrm{Q}) \rrbracket=\left\{\mathrm{X} \oplus \mathrm{Y} \mid \mathrm{X} \in{ }^{*} \mathrm{P} \cup * \mathrm{Q}, \mathrm{y} \in *^{*} \mathrm{P} \cup * \mathrm{Q}\right\} \quad \text { (Smith 2020: 66) }
$$

The ASET of an individual is defined as the inclusive mixture of the singleton set containing the individual with the ASSOC of the individual, as given in (24). Therefore, the ASET of Hla Hla in (25) contains Hla Hla, as well as the set of sums of Hla Hla with one or more of her friends, family members, and co-workers. Because of the way that the inclusive mixture is defined, the ASET of an individual contains the individual themself.

$$
\begin{gathered}
\operatorname{ASET}(\mathrm{x})=\mathrm{I}-\operatorname{Mix}(\{\mathrm{x}\}, \operatorname{ASSOC}(\mathrm{x})) \quad \text { (based on Smith 2020: 125) } \\
\operatorname{ASET}(\text { Hla Hla })=\left\{\begin{array}{c}
\text { Hla Hla }, \text { Hla Hla } \oplus \text { Aung, Hla Hla } \oplus \text { Maung Maung, } \\
\text { Hla Hla } \oplus \text { Aung } \oplus \text { Maung Maung... }\}
\end{array}\right.
\end{gathered}
$$

I propose that the associative plural tóldó contributes two components of atissue meaning: the primary meaning and the post-suppositional meaning. The primary meaning of X-tóldó denotes ' $\mathrm{X}$ and possibly their associate(s)', and the post-suppositional meaning requires that the referent contains at least one associate of X. I first consider the application of the analysis to (26) with a single plural phrase formed with tóldó. (26) requires that Hla Hla came and at least one of her associates came. The primary meaning, given in (27a), says that at least one individual in the ASET of Hla Hla came. After the context gets updated with the primary meaning, 
the post-supposition in (27b) is then checked. (27b) requires that there is at least one member of the ASSOC of Hla Hla that came. Notice that the ASET of Hla Hla required in the primary meaning can include just Hla Hla herself. This means that the primary meaning in (27a) does not itself entail satisfaction of the post-suppposition. Thus, they together require that Hla Hla and at least one associate came, which is the correct prediction.

(26) Hla Hla-dó la-géh-deh.

Hla Hla-ASSOC come-PAST-NFUT

'Hla Hla and her associate(s) came.'

Hla Hla-dó came. $=(26)$

a. primary meaning: $\exists x[x \in \operatorname{ASET}(H l a$ Hla $) \wedge \operatorname{come}(x)]$

b. post-supposition: $\exists y[y \in \operatorname{ASSOC}(H l a$ Hla $) \wedge \operatorname{come}(y)]$

c. paraphrase: Hla Hla (and associate(s)) came. At least one of Hla Hla's associates came.

Turning to conjunctions of associative plurals, let's consider the example in (28) which allows the internal plural where only Hla Hla and Aung came, as long as they are each other's associates. As shown in (29a), the primary meaning denotes some member of the set formed by the pointwise summation of the ASET of Hla Hla the ASET of Aung. Here, I assume that néh is a non-Boolean conjunction. The post-suppositions then check that some member of the ASSOC of Hla Hla came and some member of the ASSOC of Aung came. At the point of evaluating the post-suppositions, as long as Hla Hla and Aung are in a relevant social relationship, Aung can be the associate of Hla Hla satisfying the post-suppositional requirement of Hla Hla-dó and vice versa. ${ }^{4}$

$$
\begin{aligned}
& \text { Hla Hla-dó (=néh) Aun-dó la-géh-deh. } \\
& \text { Hla Hla-ASSOC =CONJ Aung-ASSOC come-PAST-NFUT } \\
& \text { 'Hla Hla and Aung (and their associate(s)) came.' }
\end{aligned}
$$

4 Notice that the post-suppositional meaning cannot simply be a requirement that the referent is nonatomic because this makes the incorrect prediction that Hla Hla-dó Aung-dó is felicitous for just Hla Hla and Aung even if they are not each other's associates. 
A post-suppositional account of associative plurals in Burmese

Hla Hla-dó Aung-dó came. $=(28)$

a. primary meaning: $\exists X[X \in\{a \oplus b \mid a \in \operatorname{ASET}($ Hla Hla $) ; b \in \operatorname{ASET}($ Aung) $\}$ $\wedge \operatorname{come}(X)]$

b. post-suppositions: $\exists y[y \in \operatorname{ASSOC}(H l a H l a) \wedge \operatorname{come}(y)]$;

$$
\exists z[z \in \operatorname{ASSOC}(\text { Aung }) \wedge \operatorname{come}(z)]
$$

c. paraphrase: Hla Hla (and associate(s)) and Aung (and associate(s)) came.

At least one of Hla Hla's associates came. At least one of

Aung's associates came.

Unlike Brasoveanu \& Szabolcsi 2013's analysis, I propose that the post-supposition of the Burmese associative particle tóldó contributes to the at-issue meaning of the sentence. This means that failure to satisfy the associative post-suppositional requirement results in a judgement of falsity. The at-issueness of the meaning of tóldó can be demonstrated by examining the entailments of a tóldó plural phrase in conditionals, as I show in (30). The entailment patterns reported in (30) reveal that the post-suppositional requirement of tóldó-and therefore its multiplicity inference-becomes part of the at-issue meaning of the conditional.

\section{tóldó in a conditional:}

[Sú=gá Hla Hla-dó=go twé-yin], Sú=gá pyaw-meh. Suu=NOM Hla Hla-ASSOC $=$ ACC meet-if Suu=NOM happy-FUT

$\rightsquigarrow$ If Suu meets Hla Hla and her associate(s), Suu will be happy.

$\rightsquigarrow$ If Suu only meets Hla Hla, Suu is not guaranteed to be happy.

$\rightsquigarrow$ If Suu only meets Hla Hla's associate(s), Suu is not guaranteed to be happy.

\subsection{Timing of evaluation}

At its core, my proposal is that the interpretation of the associative requirement of tóldó has to be delayed in order to account for the internal plural reading. In this section, I attempt to diagnose more precisely how far the interpretation of the associative requirement can be delayed. In particular, I will investigate if the internal plural reading also arises between X-tóldó phrases of separate VP conjuncts and TP conjuncts.

In Burmese, VPs are conjoined with the the post-verbal particle pi (Soe 1999: 154). As we see in (31), the sentence is infelicitous if Suu only met Hla Hla and Aung, even if they are in a contextually salient relationship. In other words, there is no internal plural reading available between X-tóldó phrases in separate VP conjuncts. 
(31) No internal plural reading with VP conjunction:

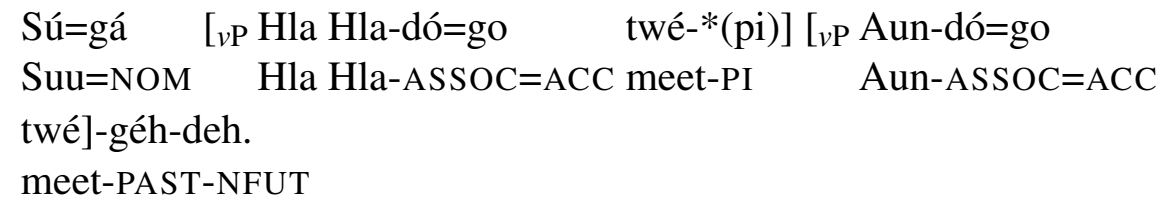

'Suu met Hla Hla and her associate(s) and met Aung and his associate(s).' False if Suu only met Hla Hla and Aung, even if they are a couple.

Likewise, the internal plural reading is not available between two X-tóldó phrases found across separate TP conjuncts. TP conjuncts are conjoined using either pi or the regular sentence-final mood ending deh. As I report in (32), the TP conjunction is infelicitous if Suu only met Hla Hla and Aung, even if they are in a contextually salient relationship.

\section{(32) No internal plural reading with TP conjunction:}

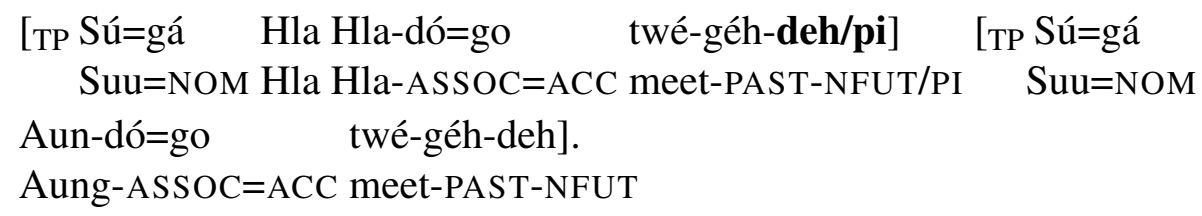

'Suu met Hla Hla and her associate(s) and Suu met Aung and his associate(s).' False if Suu only met Hla Hla and Aung, even if they are a couple.

Based on the absence of the internal plural reading in cases of VP conjunction and TP conjunction, we can conclude to that the post-supposition of tóldó must be evaluated at the minimal clausal projection, i.e. the next highest $v \mathrm{P}$ or TP node. If the evaluation of post-suppositions were allowed to be further delayed, we would expect the internal plural reading to be available across VP and TP conjunction.

\subsection{Is tó/dó an additive particle?}

Given the parallels between the data for tóldó and the Japanese data, it is reasonable to ask if tóldó is in fact an additive particle like Japanese mo. In this section, I compare tóldó to the canonical additive particle in Burmese, lèh (see e.g. Jenny \& Hnin Tun 2016: 478). I present three data points to argue that that tóldó is different from an additive particle.

First, Burmese has an optional subject-oriented plural agreement cá/já (Jenny \& Hnin Tun 2016: 217, Soe 1999: 185). As shown in (33), a tóldó subject DP triggers agreement with cá/já. 
A post-suppositional account of associative plurals in Burmese

\section{Optional plural agreement:}

S’ăya-dó la-géh-(já)-deh.

teacher-ASSOC come-PAST-PL-NFUT

'Teachers (and their associates) came.'

In contrast, cá/já cannot co-occur with an additive phrase with lèh, even if the additive requirement of lèh is satisfied by a preceding utterance. (34) illustrates this.

\section{(34) Plural agreement incompatible with singular with lèh:}

a. Hla Hla=gá la-géh-deh...

Hla Hla=NOM come-PAST-NFUT

'Hla Hla came.'

b. ... S'ăya=lèh la-géh-(*já)-deh.

teacher=also come-PAST-PL-NFUT

'The teacher also came.'

Second, the predicate twé, 'meet' when used intransitively, takes a plural subject. In (35), observe that the collective predicate can take a tóldó DP as its argument.

\section{Collective predicate compatible with tó/dó:}

Hla Hla-dó=gá caùn-hma twé-meh.

Hla Hla-ASSOC=NOM school-LOC meet-FUT

'Hla Hla and her associate(s) will meet at school.'

However, a DP with lèh is incompatible with 'meet', even if the additive requirement has been satisfied by preceding discourse.

Collective predicate incompatible with singular with lèh:

a. Aun =néh Sú=gá caùn-hma twé-meh...

Aung $=$ CONJ Suu $=$ NOM school-LOC meet-FUT

'Aung and Suu will meet at school.'

b. *... Hla Hla=gá=lèh caùn-hma twé-meh. Hla Hla=NOM=also school-LOC meet-FUT

Third and finally, a tóldó DP can bind a reciprocal argument expressed by c'ìnjìn as in (37) but an argument with lèh cannot bind c'ìnjìn, as in (38).

\section{Reciprocal argument compatible with tóldó:}

Caùndhà-dó=gá c'ìnjìn pyàw-ne-deh.

student-ASSOC=NOM RECIP talk-PROG-NFUT

'The students are talking to each other.' 


\section{Reciprocal argument incompatible with tóldó: \\ * Caùndhà=gá=lèh c'ìnjìn pyàw-ne-deh. student=NOM=also RECIP talk-PROG-NFUT}

The three data points presented above demonstrate consistently that tóldó nominals are grammatical in positions where we typically expect plural arguments. In contrast, singular nominals with lèh are ungrammatical in these very same positions.

\section{Conclusion}

In this paper, I argued that a plural DP X-tóldó has two components of at-issue meaning. First, it denotes ' $X$ and possibly associates of $X$ ' when calculating the sentence's primary meaning. After the primary meaning updates the context, there is a post-suppositional meaning whose evaluation is delayed to the minimal clausal projection. The post-supposition checks that the referent of X-tóldó includes at least one associate of $\mathrm{X}$. The motivation to delay the interpretation of tóldó in such a way comes from what I termed the internal plural reading of conjunctions of DPs formed with tóldó.

A natural question that arises is whether associative plurals across languages are necessarily post-suppositional. This is probably not the case: I am aware that Japanese is an example of a language that does not have the internal plural reading in a similar construction. In Japanese, the associative plural is tachi (Nakanishi \& Tomioka 2004; Smith 2020). The DP conjunction formed with tachi in (39) would be false if only Taro and Hanako came, even if they are known to be in a social relationship.

\section{(39) Japanese plural conjunction:}

Taro-tachi (to) Hanako-tachi $=$ ga kita. $^{5}$

Taro-ASSOC and Hanako-ASSOC $=$ NOM came

'Taro, Hanako, and their associates came.'

False if only Taro and Hanako came.

$\rightsquigarrow$ Taro, Hanako, and some unnamed associate(s) came.

On the other hand, there is at least one other language where the internal plural reading of conjoined association plurals has been observed. Yuan 2017 documents that Inuktitut has an associative plural $k k u$. When a DP formed with $k k u$ is marked by a dual marker as in (40a), there are exactly two individuals in the referent: Monica and her associate. When it is marked by a plural marker, as in (40b), then there are multiple other people besides Monica who are walking.

5 I thank Michael Yoshitaka Erlewine, Minako Erlewine, Mie Hiramoto, Yosuke Sato, Kiyoko Mori, and Sakiko Hino for discussion of this example. 
A post-suppositional account of associative plurals in Burmese

\section{(40) Inuktitut number morphology:}

a. Maanika-kku-k pisuk-tuuk.

Monica-ASSOC-DU.ABS walk-INTR.3D

'Monica and one other are walking.'

b. Maanika-kku-t pisuk-tut.

Monica-ASSOC-PL.ABS walk-INTR.3P

'Monica and others are walking.'

(Yuan 2017: 2)

The internal plural reading is observed when conjoining $k k u$ plural phrases. In particular, notice that with dual morphology in the conjuncts, (41a) must strictly refer to Monica and Ruth and no one else, since the number morphology indicates the total number of members in the group. In the case of plural morphology, (41b) may refer to just Monica, Ruth, and Susan. (41a) and (41b) seem to both be examples of the internal plural reading I have described in this paper.

\section{(41) Internal plural reading in Inuktitut:}

a. Maanika-kku-k Uruuti-kku-k Monica-ASSOC-DU Ruth-ASSOC-DU

'Monica and Ruth.'

b. Maanika-kku-t Uruuti-kku-t Suusa-kku-t Monica-ASSOC-PL Ruth-ASSOC-PL Susan-ASSOC-PL

'Monica, Ruth, and Susan'

(Yuan 2017: 5)

Further detailed work on the interpretation of conjunctions of associative plurals, in Inuktitut and other languages, will help us better understand the possible variation in the meaning of associative plurals and the grammar of post-suppositional meanings.

\section{References}

den Besten, Hans. 1996. Associative DPs. Linguistics in the Netherlands 13. 13-24. doi:10.1075/avt.13.04bes.

Brasoveanu, Adrian. 2013. Modified numerals as post-suppositions. Journal of Semantics 30. 155-209. doi:10.1093/jos/ffs003.

Brasoveanu, Adrian \& Anna Szabolcsi. 2013. Presuppositional too, postsuppositional too. In Maria Aloni, Michael Franke \& Floris Roelofsen (eds.), The Dynamic, Inquisitive, and Visionary Life of $\phi, ? \phi$, and $\diamond \phi:$ A Festschrift for Jeroen Groenendijk, Martin Stokhof, and Frank Veltman, 55-64. 
Bumford, Dylan. 2017. Split-scope definites: Relative superlatives and Haddock descriptions. Linguistics and Philosophy 40. 549-593. doi:10.1007/s10988-0179210-2.

Charlow, Simon. 2016. Post-suppositions and semantic theory. Manuscript.

Erlewine, Michael Yoshitaka \& Meghan Lim. 2020. Anti-uniqueness without articles. In Joseph Rhyne, Kaelyn Lamp, Nicole Dreier \& Chloe Kwon (eds.), Semantics and Linguistic Theory (SALT) 30, 430-449. doi:salt.v30i0.4848.

Farkas, Donka. 2002. Varieties of indefinites. In Brendan Jackson (ed.), Semantics and Linguistic Theory (SALT) 12, 59-83. Cornell University Ithaca, NY: CLC Publications. doi:10.3765/salt.v12i0.2873.

Gajewski, Jon Robert. 2005. Neg-raising: polarity and presupposition: Massachusetts Institute of Technology $\mathrm{PhD}$ dissertation.

Jenny, Mathias \& San San Hnin Tun. 2016. Burmese: A reference grammar. Routledge.

Krifka, Manfred. 2004. Bare NPs: kind-referring, indefinites, both, or neither? In Robert B. Young \& Yuping Zhou (eds.), Semantics and Linguistic Theory (SALT) 13, 280-203. Cornell University Ithaca, NY: CLC Publications. doi:10.3765/salt.v13i0.2880.

Kuhn, Jeremy. 2021. The dynamics of negative concord. Linguistics and Philosophy doi:10.1007/s10988-020-09318-3.

Lauer, Sven. 2009. Free relatives with -ever: Meaning and Use. Manuscript, Stanford University.

Lim, Meghan \& Michael Yoshitaka Erlewine. 2020. Definiteness and indefiniteness in Burmese. Slides presented at Triple A 7: The semantics of African, Asian, and Austronesian languages.

Lim, Meghan \& Michael Yoshitaka Erlewine. to appear. Definiteness and indefiniteness in Burmese. In Triple A 7, .

Löbner, Sebastian. 2000. Polarity in natural language: predication, quantification and negation in particular and characterizing sentences. Linguistics and Philosophy 23. 213-308. doi:10.1023/A:1005571202592.

Moravcsik, Edith. 2003. A semantic analysis of associative plurals. Studies in Language 27(3). 469-503. doi:10.1075/sl.27.3.02mor.

Nakanishi, Kimiko \& Satoshi Tomioka. 2004. Japanese plurals are exceptional. Journal of East Asian Linguistics 13(13). 113-140. doi:10.1023/B:JEAL.0000019058.46668.c1.

Okell, John. 1994. Burmese: An introduction to the spoken language. Northern Illinois University, Center of Southeast Asian Studies.

Okell, John. 2010. Burmese: An introduction to the spoken language. Northern Illinois University, Center of Southeast Asian Studies.

Sauerland, Uli, Jan Anderssen \& Kazuko Yatsushiro. 2005. The plural is semanti- 
A post-suppositional account of associative plurals in Burmese

cally unmarked. In Stephan Kepser \& Marga Reis (eds.), Linguistic Evidence: Empirical, Theoretical, and Computational Perspectives, Berlin: de Gruyter. doi:https://doi.org/10.1515/9783110197549.413.

Schwarzschild, Roger. 1996. Pluralities. Dordrecht: Kluwer Academic.

Simpson, Andrew. 2005. Classifiers and DP structure in Southeast Asia. In Guglielmo Cinque \& Richard Kayne (eds.), The Oxford Handbook of Comparative Syntax, 806-838. Oxoford University Press.

Smith, Ryan Walter. 2020. Similative plurals and the nature of alternatives: The University of Arizona PhD dissertation.

Soe, Myint. 1999. A grammar of Burmese: University of Oregon PhD dissertation. Spector, Benjamin. 2007. Aspects of the pragmatics of plural morphology: On higher-order implicatures. In Uli Sauerland \& Penka Stateva (eds.), Presupposition and Implicature in Compositional Semantics, 243-281. Palgrave Macmillan UK. doi:10.1057/9780230210752_9.

Yuan, Michelle. 2017. Towards a unified analysis of associative plurals and plural pronouns in Inuktitut. Handout presented at MIT Syntax Square.

Zweig, Eytan. 2009. Number-neutral bare plurals and the multiplicity implicature. Linguistics and Philosophy 32. 353-407. doi:10.1007/s10988-009-9064-3.

Keely New

MIT Linguistics and Philosophy

77 Massachusetts Avenue, 32-D808

Cambridge, MA, 02139, USA

knew@mit.edu 